\title{
Correction: López-Yerena, A., et al. "Absorption and Intestinal Metabolic Profile of Oleocanthal in Rats" Pharmaceutics 2020, 12, 134
}

\author{
Anallely López-Yerena ${ }^{1}{ }^{(0}$, Anna Vallverdú-Queralt ${ }^{1,2}{ }^{\circledR}$, Raf Mols $^{3}$, Patrick Augustijns ${ }^{3}{ }^{(0}$,
} Rosa M. Lamuela-Raventós ${ }^{1,2}$ (D) and Elvira Escribano-Ferrer ${ }^{2,4, *}$

1 Nutrition, Food Science and Gastronomy Department, XaRTA, Institute of Nutrition and Food Safety (INSA-UB), School of Pharmacy and Food Sciences, University of Barcelona, 08028 Barcelona, Spain; naye.yerena@gmail.com (A.L.-Y.); avallverdu@ub.edu (A.V.-Q.); lamuela@ub.edu (R.M.L.-R.)

2 CIBER Physiopathology of Obesity and Nutrition (CIBEROBN), Institute of Health Carlos III, 28029 Madrid, Spain

3 Drug Delivery and Disposition, KU Leuven, 3000 Leuven, Belgium; raf.mols@kuleuven.be (R.M.); patrick.augustijns@pharm.kuleuven.be (P.A.)

4 Department of Pharmacy and Pharmaceutical Technology and Physical Chemistry, Biopharmaceutics and Pharmacokinetics Unit, Institute of Nanoscience and Nanotechnology (IN2UB), Pharmacy and Food Sciences School, University of Barcelona, 08028 Barcelona, Spain

* Correspondence: eescribano@ub.edu; Tel.: +34-93402-4578; Fax: +34-93403-5937

Received: 25 November 2020; Accepted: 8 December 2020; Published: 17 December 2020

The authors would like to make the following corrections to this paper [1]:

\section{Change in Equation (1)}

We have found two typographical errors in Equation (1) and we wish to replace

$$
P_{\text {eff }}=\frac{-\varnothing_{\text {in }}}{2 \pi R L} \times \operatorname{Ln} \frac{C_{\text {in }}}{C_{\text {out.cor }}}
$$

With

$$
P_{\text {eff }}=\frac{-\varnothing_{\text {in }}}{2 \pi R L} \times \operatorname{Ln} \frac{C_{\text {out.cor }}}{C_{\text {in }}}
$$

\section{Change in Table 2}

We have found a typographical error in the $P_{\text {eff }}$ heading in Table 2 . In addition, and after reviewing the calculations again, we have detected that the data shown in Table 2 for levofloxacin did not consider the normalization of the $10-\mathrm{cm}$ intestinal segment. With the normalization, the $P_{\text {eff }}$ value for levofloxacin increases (according to the length of the intestinal segment used). For these reasons, the authors wish to replace

Table 2. Permeability coefficients $\left(P_{\text {eff }}\right)$ and apparent permeability coefficients $\left(P_{\text {app }}\right)$ of oleocanthal and levofloxacin. Results are expressed as the mean \pm SD of $n=4$. Data are normalised to a $10-\mathrm{cm}$ intestinal segment.

\begin{tabular}{ccc}
\hline Test Compound & $\boldsymbol{P}_{\text {eff }}\left(\times \mathbf{1 0}^{-\mathbf{5}} \mathbf{~ c m} / \mathbf{s}\right)$ & $\boldsymbol{P}_{\text {app }}\left(\times \mathbf{1 0}^{-\mathbf{6}} \mathbf{~ c m} / \mathbf{s}\right)$ \\
\hline OLC & $2.23 \pm 3.16$ & $4.12{ }^{*} \pm 2.33$ \\
LEV & $7.64 \pm 5.55$ & $10.91 \pm 6.27$ \\
\hline \multicolumn{3}{c}{${ }^{*} p<0.05$, Mann-Whitney U-test. }
\end{tabular}


With

Table 2. Permeability coefficients $\left(P_{\text {eff }}\right)$ and apparent permeability coefficients $\left(P_{\text {app }}\right)$ of oleocanthal and levofloxacin. Results are expressed as the mean \pm SD of $n=4$. Data are normalised to a 10-cm intestinal segment.

\begin{tabular}{ccc}
\hline Test Compound & $\boldsymbol{P}_{\text {eff }}\left(\times \mathbf{1 0}^{-\mathbf{4}} \mathbf{~ c m} / \mathbf{s}\right)$ & $\boldsymbol{P}_{\text {app }}\left(\times \mathbf{1 0}^{-\mathbf{6}} \mathbf{~ c m} / \mathbf{s}\right)$ \\
\hline OLC & $2.85 \pm 2.63$ & $4.12 * \pm 2.33$ \\
LEV & $12.69 \pm 6.64$ & $10.91 \pm 6.27$ \\
\hline \multicolumn{3}{c}{}
\end{tabular}

These changes do not affect the discussion and conclusions of the study. The authors would like to apologize for any inconvenience caused to the readers by these changes.

Conflicts of Interest: R.M.L.-R. reports receiving lecture fees from Cerveceros de España and receiving lecture fees and travel support from Adventia. The other authors declare no conflict of interest. The funders had no role in the design of the study; in the collection, analyses, or interpretation of data; in the writing of the manuscript, or in the decision to publish the results.

\section{Reference}

1. López-Yerena, A.; Vallverdú-Queralt, A.; Mols, R.; Augustijns, P.; Lamuela-Raventós, R.M.; Escribano-Ferrer, E. Absorption and Intestinal Metabolic Profile of Oleocanthal in Rats. Pharmaceutics 2020, 12, 134. [CrossRef]

Publisher's Note: MDPI stays neutral with regard to jurisdictional claims in published maps and institutional affiliations.

(C) 2020 by the authors. Licensee MDPI, Basel, Switzerland. This article is an open access article distributed under the terms and conditions of the Creative Commons Attribution (CC BY) license (http://creativecommons.org/licenses/by/4.0/). 